Provided for non-commercial research and education use. Not for reproduction, distribution or commercial use.

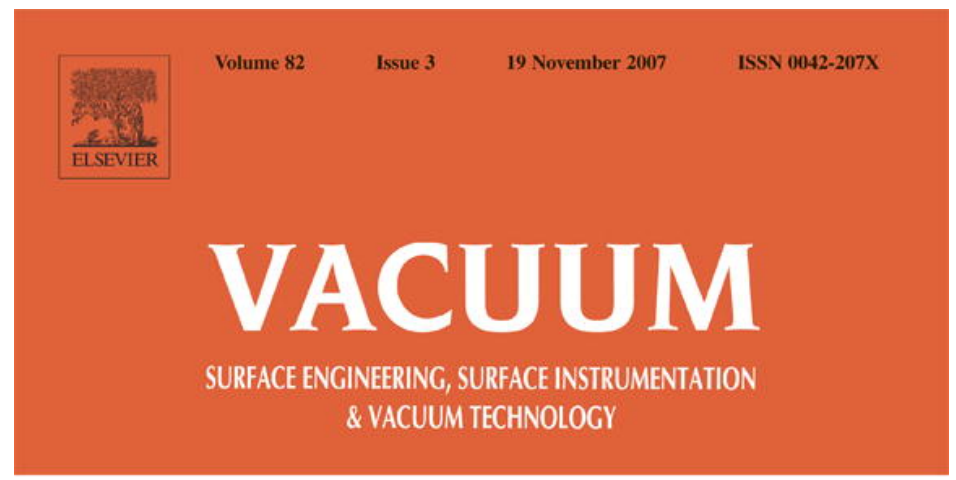

EDITORS
JOHN S COLLIGON GREGORY J EXARHOS LARS G HULTMAN RICHARD E HURLEY KIYOTAKA WASA

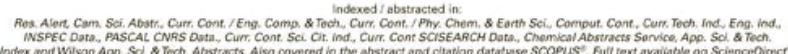

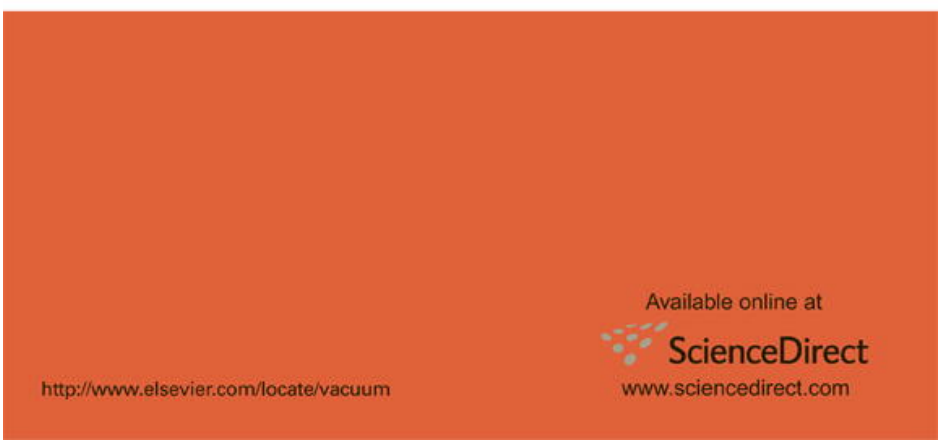

This article was published in an Elsevier journal. The attached copy

is furnished to the author for non-commercial research and education use, including for instruction at the author's institution, sharing with colleagues and providing to institution administration.

Other uses, including reproduction and distribution, or selling or licensing copies, or posting to personal, institutional or third party websites are prohibited.

In most cases authors are permitted to post their version of the article (e.g. in Word or Tex form) to their personal website or institutional repository. Authors requiring further information regarding Elsevier's archiving and manuscript policies are encouraged to visit:

http://www.elsevier.com/copyright 


\title{
Applying RF current harmonics for end-point detection during etching multi-layered substrates and cleaning discharge chambers with $\mathrm{NF}_{3}$ discharge
}

\author{
V. Lisovskiy ${ }^{\mathrm{a}, *}$, J.-P. Booth $^{\mathrm{b}}$, K. Landry ${ }^{\mathrm{c}}$, D. Douai ${ }^{\mathrm{d}}$, V. Cassagne ${ }^{\mathrm{e}}$, V. Yegorenkov ${ }^{\mathrm{f}}$ \\ ${ }^{a}$ Department of Physics and Technology, Kharkov National University, Kharkov 61077, Ukraine \\ ${ }^{\mathrm{b}}$ Laboratoire de Physique et Technologie des Plasmas, Ecole Polytechnique, Palaiseau 91128, France \\ ${ }^{\mathrm{c}}$ Unaxis Displays Division France SAS, 5, Rue Leon Blum, Palaiseau 91120, France \\ d Association Euratom-CEA, Département de Recherches sur la Fusion Contrôlée, CEA Cadarache, F-13108 Saint Paul lez Durance Cedex, France \\ ${ }^{\mathrm{e}}$ Riber, 31 rue Casimir Périer, 95873 Bezons, France \\ ${ }^{\mathrm{f}}$ Department of Physics, Kharkov National University, Kharkov 61077, Ukraine
}

Received 12 June 2006; received in revised form 19 April 2007; accepted 19 April 2007

\begin{abstract}
The present paper reports the results of studying the characteristics of the etching process of multi-layered materials $\left(\mathrm{Si}_{3} \mathrm{~N}_{4} / \mathrm{SiO}_{2} / \mathrm{Si}\right.$ and $\left.\mathrm{SiO}_{2} / \mathrm{Si}\right)$ and of cleaning technological chambers covered with silicon nitride films $\left(\mathrm{Si}_{3} \mathrm{~N}_{4}\right)$ in a $\mathrm{NF}_{3} \mathrm{RF}$ capacitive discharge. The process of chamber cleaning was monitored with a mass spectrometer. The gas pressure, RF voltage amplitude, current-voltage phase shift, ohmic current as well as the second harmonic of the RF current were also recorded. The opportunity of using these parameters for end-point detection of etching and plasma cleaning is discussed. It is found that the second harmonic of the RF current may be successfully used for end-point detection of multi-layered materials etching and to monitor the cleaning process of technological chambers. The cleaning of chambers of complicated design may possess a double-stage pattern.
\end{abstract}

(C) 2007 Elsevier Ltd. All rights reserved.

Keywords: $\mathrm{NF}_{3}$; $\mathrm{RF}$ discharge; Etching; Cleaning; End-point

\section{Introduction}

Plasma etching (using gas discharges in chemically active gases to etch solid surfaces) is an important composite process in microelectronics processing [1-4]. During etching the surface material is selectively removed by chemical reactions and/or physical sputtering. In the gases usually used for etching $\left(\mathrm{CF}_{4}+\mathrm{O}_{2}, \mathrm{SF}_{6}+\mathrm{O}_{2}, \mathrm{NF}_{3}\right.$, etc. $)$, which are stable under normal conditions and do not participate in any reaction with different materials, fluorine atoms as well as radicals $\left(\mathrm{CF}_{x}, \mathrm{SF}_{x}, \mathrm{NF}_{x}\right)$ are formed by dissociation in the gas electric discharge. Fluorine atoms diffuse to the surface of the materials under processing and participate in surface reactions that form volatile products $\left(\mathrm{SiF}_{4}\right.$ when

\footnotetext{
${ }^{*}$ Corresponding author. Tel.: + 380573352550 ; fax: + 380573352530 .

E-mail address: lisovskiy@yahoo.com (V. Lisovskiy).
}

etching silicon-containing wafers- $-\mathrm{Si}, \mathrm{SiO}_{2}, \mathrm{Si}_{3} \mathrm{~N}_{4}$, etc.) that evaporate from the surface and are further pumped out of the discharge volume. Etching in gas discharge plasma is also used for cleaning and polishing surfaces, processing plate edges, cutting plates into separate crystals, etc.

Plasma cleaning is a form of etching and is also based on a combination of chemical reactions between surface impurities and radicals formed in the discharge volume and on the surface, and sputtering through ion bombardment. Plasma cleaning was first developed for surface preparation of large vacuum vessels used to accelerate charged particles and as thermonuclear fusion devices [5-11]. However, plasma cleaning began later to be widely applied in various technological processes: degassing the surfaces of discharge vessels, cleaning silicon wafers from carbon impurities, removing impurities from the electrodes 
and walls of technological vessels which had formed during deposition of semiconducting and polymer materials, cleaning plane items and other devices from lubricants, grease removal and preparation of surfaces for dying, removal of metallic impurities from the surfaces of ceramic insulators, restoration of metallic archaeological artefacts, etc. [12-25].

Great attention is devoted to the means to monitor the processes of plasma etching and cleaning. The matter is that etching processes do not terminate at the boundary between the films of the material to be etched and the under-layer (wafer). When the layer of the material to be etched is removed, which defines the moment of time called the end-point of the etching process (plasma cleaning), the gas discharge must be switched off to avoid excessive etching of the sub-layer.

In the case of plasma cleaning of surface impurities, no etching of the discharge vessel walls actually occurs, however, e.g., the aluminium electrodes and other surfaces are covered with an $\mathrm{AlF}_{3}$ dielectric layer by reaction with fluorine. Therefore, it is important to quench the discharge immediately after finishing the plasma cleaning process.

Many methods for process end-point determination may be found in the literature. Optical emission spectroscopy is the most widely used technique [26-29]. Optical emission observed when plasma etching is under way is due to transitions between electron excitation states of the gases used for etching as well as of their fragments (radicals).

Photometric process is applied for the process end-point determination as well as for measuring the etch rate. The time variation of the reflection coefficient of the film under etching is registered. Here, laser interferometry [27,30,31] as well as ellipsometry [32] may be used.

Laser-induced fluorescence that permits to register $\mathrm{SiF}_{2}$, $\mathrm{CF}$ and $\mathrm{CF}_{2}$ molecules [33-36], the recording and analysis of the UV absorption spectrum for determining $\mathrm{CF}$ and $\mathrm{CF}_{2}$ concentrations [37] and IR absorption spectroscopy [38-40] that permits to determine the type and concentration of molecules present in the discharge volume, may be attributed to the optic methods of monitoring the etching process.

Mass spectrometry is a reliable diagnostic method for gas-discharge plasma. This method does not disturb the discharge [30,32,41-44]. For detecting the process end point, a flow of neutral gas leaving the plasma reactor is analysed. The peak of $\mathrm{SiF}_{3}^{+}$, with $m / e=85 \mathrm{amu}$, is usually used to monitor the etching process and its end point in the case of silicon and silicon-containing materials in fluorinecontaining gases $\left(\mathrm{CF}_{4}, \mathrm{SF}_{6}, \mathrm{NF}_{3}\right) . \mathrm{SiF}_{4}$ is a product of the reactions of several compounds with fluorine, but each compound produces $\mathrm{SiF}_{4}$ with a characteristic rate for given conditions in the gas discharge.

Another method consists in monitoring the discharge impedance $[31,45]$ which varies due to variations in the chemical composition of the discharge at the end point of the process (and, as a consequence, variations in physical characteristics: plasma density, electron temperature, plasma potential, etc.).

Gas pressure monitoring during etching and cleaning is maybe the simplest method of end-point detection $[31,46]$. During etching in chemically active gases, a solid material transforms into volatile species, this contributes to a change in gas pressure.

Langmuir probes may also be used to monitor the etching process and end-point detection [47-49]. But a probe should be located in the discharge volume thereby disturbing the plasma. Furthermore, there is a risk that the etching products re-deposit on the probe surfaces, or that the probe material itself is etched. This would lead to changes in the probe current which may have no relation to the process end point.

Recently, the variation of RF voltage harmonics in burning discharges began to be employed for end-point detection [50-53]. The authors of these papers demonstrated that certain harmonics (from 5 to 8 ) turn out to be sensitive to changes in the discharge during the removal of photoresist from the silicon surface in RF discharge in oxygen, and as such may be used for the process end-point detection. The authors of paper [54] performed a theoretical treatment of this method.

Fluorine-containing gases such as $\mathrm{CF}_{4}, \mathrm{SF}_{6}$ and $\mathrm{NF}_{3}$, used in the microelectronic industry attract an evergrowing attention because of their role in global warming [55]. The dissociation degree of fluorine-containing gases in RF discharges is usually in the range of $15-70 \%$, depending on the discharge conditions and the gas species used.

$\mathrm{NF}_{3}$ is the fluorine-containing gas the least dangerous for the environment [55]. Another advantage of $\mathrm{NF}_{3}$ is that it does not deposit films of carbon, sulphur or polymers in a burning discharge. Again, in pure $\mathrm{NF}_{3}$ the dissociated molecules do not recombine back to $\mathrm{NF}_{3}$, and mostly nitrogen and fluorine are removed from the discharge chamber into the atmosphere without greenhouse effect at all.

The objective of this paper is to study the time dependence of the etching characteristics of multi-layered materials $\left(\mathrm{Si}_{3} \mathrm{~N}_{4} / \mathrm{SiO}_{2} / \mathrm{Si}\right.$ and $\left.\mathrm{SiO}_{2} / \mathrm{Si}\right)$ and of the plasma cleaning characteristics of technological chambers covered with silicon nitride $\left(\mathrm{Si}_{3} \mathrm{~N}_{4}\right)$ films, in $\mathrm{NF}_{3} \mathrm{RF}$ capacitive discharges. Etching and chamber cleaning processes were monitored with mass spectrometry, and by registering gas pressure, RF voltage amplitude, phase shift angle between current and voltage, ohmic current, active power as well as the magnitude of the second harmonic of RF current. We found that registering the magnitude of the second harmonic of the RF current may be successfully applied for end-point detection while etching multi-layered materials as well as for monitoring the process of chamber plasma cleaning. It is shown that cleaning a chamber with a complicated design may be a two-stage process. 


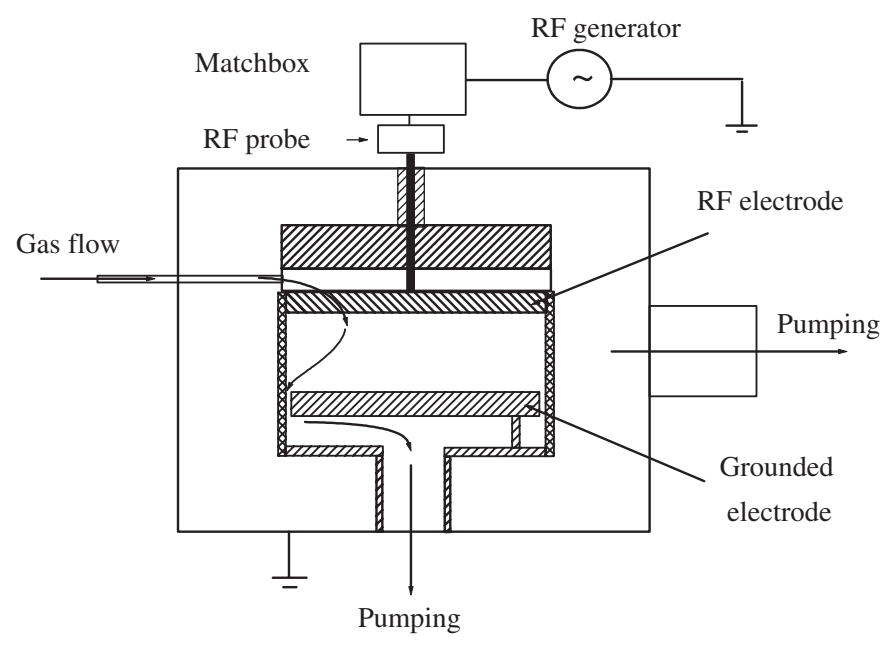

Fig. 1. Experimental chamber design.

\section{Description of the experiment}

The frequency of the RF field was $f=13.56 \mathrm{MHz}$ in the present experimental set-up. The experiments were conducted with $\mathrm{NF}_{3}$ in the gas pressure range $p \approx 0.075-0.375$ Torr $(0.1-0.5 \mathrm{mbar})$ with an interelectrode distance of $d=25 \mathrm{~mm}$. The flat and round aluminium electrodes had a diameter of $143 \mathrm{~mm}$. The RF voltage with amplitude $U_{\mathrm{RF}}<1300 \mathrm{~V}$ was fed through the matchbox to the powered electrode, while another electrode was grounded. Electrodes were located inside a fused silica tube with an inner diameter of $145 \mathrm{~mm}$. The gas under study was fed into the inner chamber through small orifices in one electrode and then pumped out through the gap between the second electrode and the wall of the fused silica tube. This discharge chamber was totally surrounded with a grounded grid and put inside a large grounded chamber with a diameter of $315 \mathrm{~mm}$ and a height of $231 \mathrm{~mm}$ (so-called "Plasma Box" [15], see Fig. 1). The grounded grid, the fused silica tube around the electrodes and a lower gas pressure (by 1-2 orders of magnitude) in the large chamber prevented the ignition of a self-sustained RF discharge in it.

The effective RF voltage $U_{\text {rms }}$ was measured with an RF probe (RF probe Z'SCAN, Advanced Energy). This RF probe was located at the minimum possible distance from the RF electrode. Z'SCAN permitted to register not only the effective values of RF voltage, RF current, phase shift angle $\varphi$ between current and voltage and active power for the basic frequency but also the values of RF current and voltage for harmonics. In our experiment, we limited ourselves to the parameters of the basic frequency and the magnitude of the second harmonic of the RF current. We employed an RF generator RF5S (RF Power Products Inc.) and a matching box PFM (Huttinger Elektronik Gmbh) of L-type.

The gas pressure was monitored with 10 and 1000 Torr capacitive manometers (MKS Instruments). The gas flow was fixed with a mass flow controller to $5 \mathrm{sccm}$, and the pressure regulated by throttling the outlet to the pump. A pressure controller (adaptive pressure controller) maintained constant gas pressure.

A quadruple mass spectrometer QMS 421 (Balzers) analysed the content of the neutral gas leaving the discharge chamber. The gas under analysis was fed from the chamber through a narrow capillary that permitted to make gas analysis up to a pressure of 1 Torr.

We performed experiments with two kinds of samples$\mathrm{Si}_{3} \mathrm{~N}_{4} / \mathrm{SiO}_{2} / \mathrm{Si}$ and $\mathrm{SiO}_{2} / \mathrm{Si}$. The $\mathrm{Si}_{3} \mathrm{~N}_{4} / \mathrm{SiO}_{2} / \mathrm{Si}$ samples consisted of a silicon substrate, $75 \mathrm{~mm}$ in diameter, coated by a $450-n m$ thick $\mathrm{SiO}_{2}$ layer, coated itself by a $140-\mathrm{nm}$ thick $\mathrm{Si}_{3} \mathrm{~N}_{4}$ layer. The $\mathrm{SiO}_{2} / \mathrm{Si}$ samples were made of a silicon plate $100 \mathrm{~mm}$ in diameter coated by a $200-\mathrm{nm}$ thick $\mathrm{SiO}_{2}$ layer.

Before the experiments on plasma cleaning, a small sample of borosilicate glass was put on the lower (grounded) electrode, a mixture of silane, ammonia, hydrogen and nitrogen gases was then fed into the chamber (the mixture content was chosen in order to deposit a film with given characteristics). Then, after the film deposition, the chamber was opened, and the sample was taken out to measure the thickness of the deposited film. In the results reported in this article the film thickness was around $200 \mathrm{~nm}$. After that, we evacuated the chamber again, fed $\mathrm{NF}_{3}$ to a given pressure and then cleaned the chamber from the deposited film in the RF discharge.

\section{Results of experiments}

In the gas discharge plasma free electrons having acquired a high energy from the RF field collide with gas molecules and not only excite and ionise them but may also lead to their dissociation. In $\mathrm{NF}_{3}$, due to a relatively low bonding energy (around $2.5 \mathrm{eV}$ ), gas molecules dissociate easily as a result of collisions with electrons:

$\mathrm{NF}_{3}+\mathrm{e} \rightarrow \mathrm{NF}_{2}+\mathrm{F}+\mathrm{e}$,

$\mathrm{NF}_{2}+\mathrm{e} \rightarrow \mathrm{NF}+\mathrm{F}+\mathrm{e}$

$\mathrm{NF}+\mathrm{e} \rightarrow \mathrm{N}+\mathrm{F}+\mathrm{e}$

At the same time, reactions can occur between newly formed radicals:

$\mathrm{NF}+\mathrm{NF} \rightarrow \mathrm{N}_{2}+2 \mathrm{~F}$,

$\mathrm{NF}+\mathrm{NF}_{2} \rightarrow \mathrm{N}_{2}+3 \mathrm{~F}$,

$\mathrm{NF}_{2}+\mathrm{NF}_{2} \rightarrow \mathrm{N}_{2}+4 \mathrm{~F}$.

As a result of all these reactions, a large number of fluorine atoms are produced, which, after reaching the surface of the silicon-containing material (wafer, film, etc.), react with silicon:

$\mathrm{Si}+2 \mathrm{~F} \rightarrow \mathrm{SiF}_{2}$

$\mathrm{SiF}_{2}+2 \mathrm{~F} \rightarrow \mathrm{SiF}_{4}$ 
As a result, volatile $\mathrm{SiF}_{4}$ molecules are produced and they evaporate from the surface under processing. The solid material of the wafer (film) is removed, and etching takes place (or cleaning from silicon-containing impurities of the walls and electrodes of the discharge chamber). The $\mathrm{SiF}_{4}$ molecules can also dissociate in the gas discharge by collision with high-energy electrons:

$\mathrm{SiF}_{4}+\mathrm{e} \rightarrow \mathrm{SiF}_{x}+(4-x) \mathrm{F}+\mathrm{e} \quad(x=3,2,1)$.

A gas mixture of complex composition leaves the discharge chamber (Fig. 2a). The mixture consists of $\mathrm{NF}_{3}, \mathrm{NF}_{2}, \mathrm{NF}$, $\mathrm{N}, \mathrm{F}, \mathrm{N}_{2}, \mathrm{~F}_{2}$ molecules as well as of the products of silicon etching such as $\mathrm{SiF}_{4}, \mathrm{SiF}_{3}, \mathrm{SiF}_{2}, \mathrm{SiF}$. It is clear from the figure that $\mathrm{N}_{2}^{+}$and $\mathrm{SiF}_{3}^{+}$are the most intense peaks. The time dependence of the $\mathrm{SiF}_{3}^{+}$peak intensity (85 amu) actually describes the behaviour of the concentration of volatile reaction products $\mathrm{SiF}_{4}$, which is very convenient for monitoring the process of etching (cleaning). When the walls and electrodes of the technological chamber are completely cleaned, the intensity of the $\mathrm{SiF}_{4}^{+}, \mathrm{SiF}_{3}^{+}, \mathrm{SiF}_{2}^{+}$ and $\mathrm{SiF}^{+}$peaks decreases fast and, after complete removal of these reaction products from the chamber by the pumping system, we only observe the $\mathrm{NF}_{3}^{+}, \mathrm{NF}_{2}^{+}$(usually it is the most intense peak, $m / e=52 \mathrm{amu}), \mathrm{NF}^{+}, \mathrm{N}^{+}, \mathrm{F}^{+}$, $\mathrm{N}_{2}^{+}$peaks (Fig. 2b). The mass spectrometer registers also a certain amount of $\mathrm{O}_{2}, \mathrm{~N}_{2} \mathrm{O}, \mathrm{H}_{2}, \mathrm{H}$ and $\mathrm{OH}$, whose peak

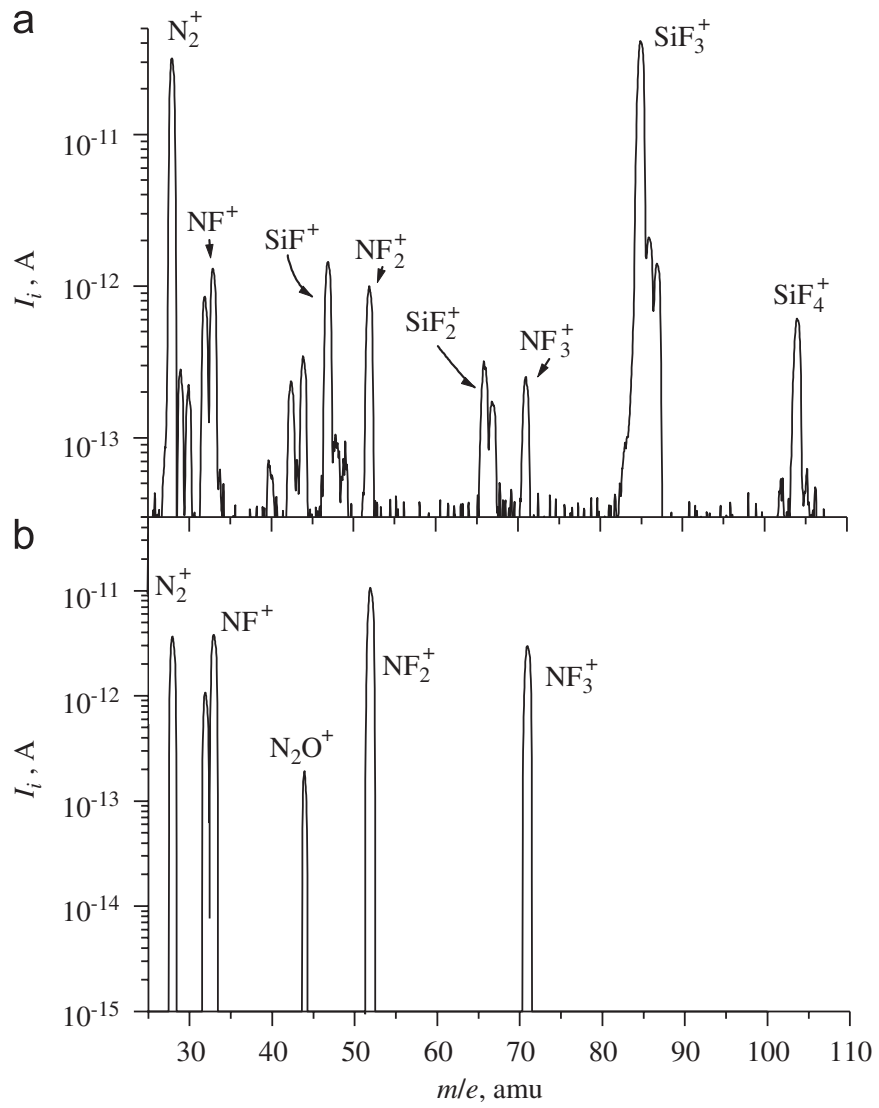

Fig. 2. Mass spectra for the cleaning process (a) and clean electrodes (b). $\mathrm{NF}_{3}, p=0.375$ Torr, $P_{\mathrm{dlv}}=75 \mathrm{~W}$. intensities do not depend on discharge conditions and therefore, are clearly determined by the residual vacuum in the mass spectrometer itself. The concentrations of atomic and molecular fluorine $\mathrm{F}$ and $\mathrm{F}_{2}$, registered with our mass spectrometer, also hardly correspond to the actual concentration of fluorine in the discharge. The gas is pumped out from the discharge chamber through a narrow gap between the grounded electrode and the wall, and then a portion of the gas is fed through a narrow capillary into the mass spectrometer. Chemically active fluorine has enough time to react with the surface of the electrode, fused silica tube and capillary walls and as a result the $\mathrm{F}_{2}^{+}$ (38 amu) peak may often be absent from the mass spectrum.

Let us consider first our plasma cleaning results for a discharge chamber with a complicated design. In this case, a considerable quantity of silicon-containing film may be deposited outside of the flat surface of the electrodes or of the wall of the fused silica tube. For this, we made 140 cylindrical indentations $(3.3 \mathrm{~mm}$ in diameter and $6 \mathrm{~mm}$ deep) uniformly distributed in the grounded electrode ( $1 \mathrm{~cm}$ thick aluminium disc). Then, during silicon nitride deposition the film was not only deposited on the flat electrodes but also on the lateral walls of the indentations and on their flat bottoms. We made no estimation of the thickness of the film deposited on the walls of indentations but it was certainly larger than on the surface of the electrodes. The reason is that in every indentation a hollow cathode discharge was burning during film deposition with a glow somewhat brighter than the discharge glow near flat parts of the electrode close to it. A brighter glow indicates the presence of denser and hotter plasma, and, consequently, a higher rate of film deposition.

Then, we performed plasma cleaning using all the methods of diagnosing the ongoing process at our disposal: mass spectrometry, registering of gas pressure $p$, effective RF voltage $U_{\text {rms }}$, RF current (rms current $I_{\text {rms }}$, as well as active current $I_{\mathrm{RF}} \cos (\varphi)$ ), phase shift angle between current and voltage $\varphi$, magnitude of the second harmonic of the discharge current $I_{\mathrm{rms} 2}$. All results obtained in this experiment are depicted in Fig. 3. At the $\mathrm{NF}_{3}$ pressure of 0.375 Torr, the discharge burned in the normal mode directly after ignition, occupying only a part of the electrode surface, and gradually cleaned the electrode surfaces and a part of the discharge tube wall in contact with the electrode. After almost complete cleaning of this region, the discharge shifted in a jump to a new area covered with film. Such jumps were associated with jumps of discharge parameters. The time was counted from the moment the RF generator was switched on. Just after ignition, the RF voltage decreased abruptly from 200 to $140 \mathrm{~V}$. After moving several times from a cleaned area to a contaminated one, the discharge gradually removed the film from the flat surface of the electrodes and from the walls of the fused silica tube. Before completion of this process, the RF voltage, the active current $I_{\mathrm{RF}} \cos (\varphi)$ and the phase shift angle $\varphi$ increased considerably. Then, after 


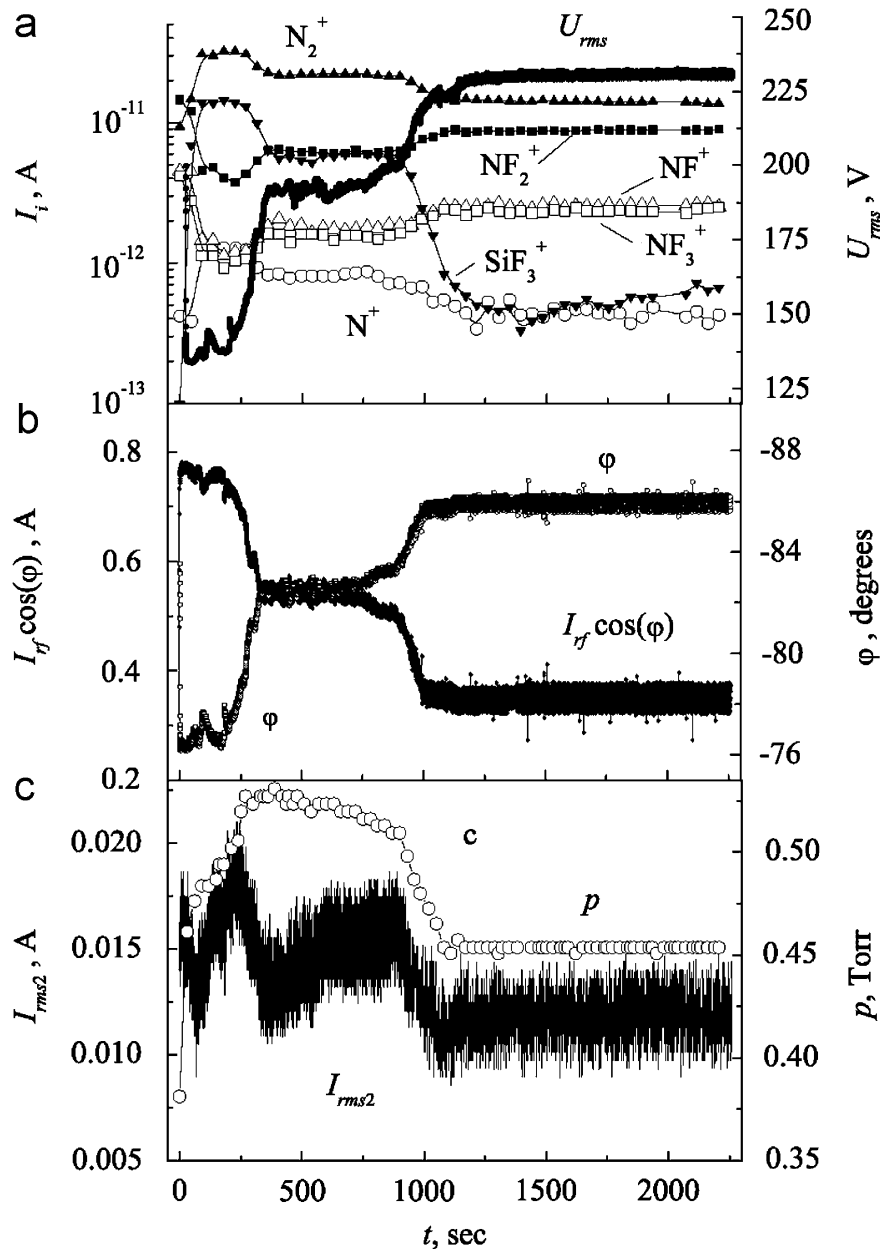

Fig. 3. Time dependence of the $\mathrm{N}^{+}, \mathrm{N}_{2}^{+}, \mathrm{NF}^{+}, \mathrm{NF}_{2}^{+}, \mathrm{NF}_{3}^{+}, \mathrm{SiF}_{3}^{+}$peak intensities and the RF voltage $U_{\text {rms }}$ (a), phase shift angle $\varphi$ and active RF current $I_{\mathrm{RF}} \cos (\varphi)(\mathrm{b})$, the magnitude of the second harmonic of the discharge current $I_{\mathrm{rms} 2}$ and gas pressure $p$ (c) under plasma cleaning of a silicon nitride film in $\mathrm{NF}_{3}$, initial pressure $p=0.375$ Torr, $P_{\mathrm{dlv}}=50 \mathrm{~W}$. The grounded electrode possesses 140 indentations.

the discharge had changed into the anomalous mode and covered the whole surface of the electrodes, the discharge parameters stabilised at $t>350 \mathrm{~s}$ for some time, during which fluorine atoms and molecules continued to remove the remainder of the film deposited on the walls of the indentations in the grounded electrode. When the cleaning of the orifices was coming to an end, the RF voltage, active RF current $I_{\mathrm{RF}} \cos (\varphi)$ and phase shift angle $\varphi$ increased again. The magnitude of the second harmonic of the discharge current $I_{\text {rms2 }}$ behaved somewhat differently than $U_{\mathrm{rms}}, I_{\mathrm{RF}} \cos (\varphi)$ and $\varphi$ during the cleaning process. While the discharge cleaned a given part of the chamber, $I_{\mathrm{rms} 2}$ increased; however, on completing the cleaning process of this part, $I_{\mathrm{rms} 2}$ decreased. In the figure, we observe two sections with a considerable decrease in $I_{\text {rms } 2}$, namely, when the discharge completed the cleaning of the flat surface of the electrodes and of the fused silica tube walls (the first stage of cleaning), and when the remainder of the film was removed from the walls of the indentations in the electrode (the second stage of cleaning). Consequently, the process of cleaning a chamber with a complicated design and non-uniform distribution of the deposited film is accomplished in two stages, which should be kept in mind when cleaning large technological chambers. After the complete cleaning of the chamber from the silicon nitride film, all registered parameters remained stable except the intensity of the $\mathrm{SiF}_{3}^{+}$peak, which began to increase slowly again after approaching its minimum. This was probably associated with chamber heating and enhanced etching of the walls of the fused silica tube.

During this experiment, the gas pressure in the chamber first increased abruptly after ignition, then decreased smoothly to a certain value, without dogleg features. When the discharge finished to clean the walls of the orifices in the electrode and all discharge parameters exhibited jump-like behaviour, the gas pressure also quickly decreased and then stabilised, after the cleaning process ended. Such a behaviour of the gas pressure indicates that its time dependence still enables a reliable determination of the end-point of plasma cleaning, though it is not very sensitive to "fine" processes in the discharge chamber.

Now consider how electrical parameters vary during the etching of multi-layered semiconductor and dielectric materials. Fig. 4 depicts the results for $\mathrm{SiO}_{2} / \mathrm{Si}$ plates at the $\mathrm{NF}_{3}$ pressure of 0.075 Torr. The discharge burned in the anomalous mode, totally filling the discharge chamber. Under conditions of Fig. 4, just after ignition, the RF voltage, active RF current and phase shift angle experienced a jump and then remained stable for almost $150 \mathrm{~s}$.

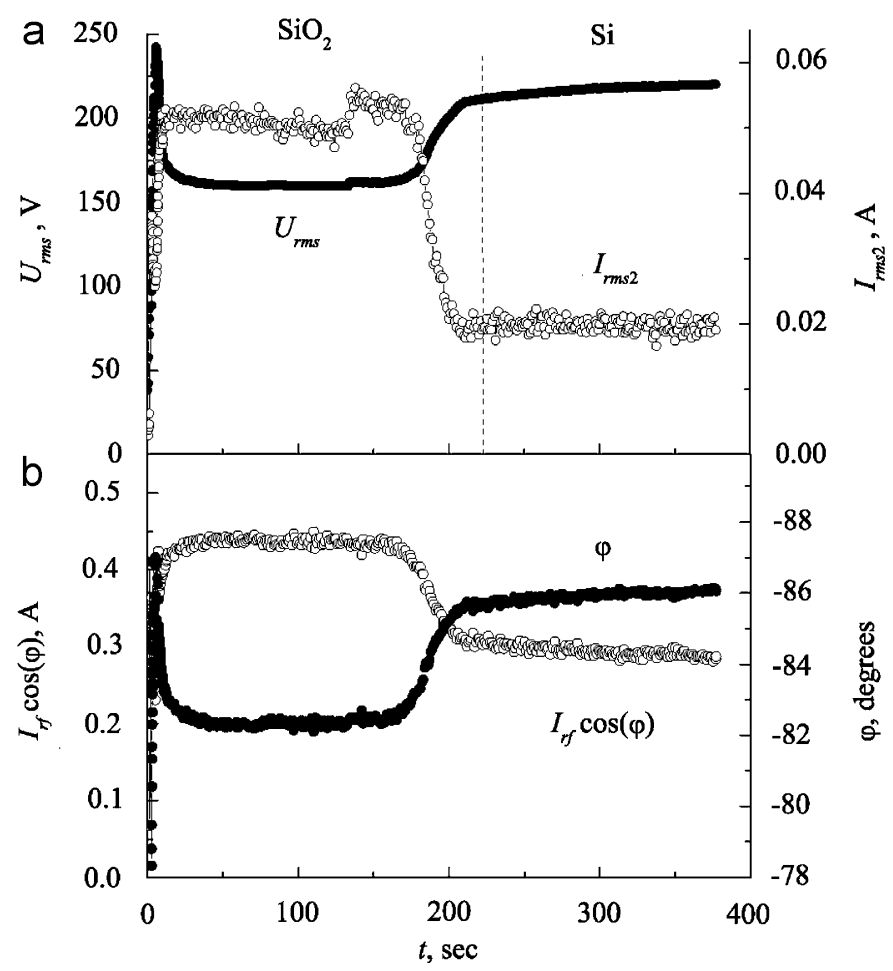

Fig. 4. Time dependence of the RF voltage $U_{\text {rms }}$ and magnitude of the second harmonic of the discharge current $I_{\mathrm{rms} 2}$ (a), phase shift angle $\varphi$ and active RF current $I_{\mathrm{RF}} \cos (\varphi)$ (b) during etching of an $\mathrm{SiO}_{2} / \mathrm{Si}$ substrate in $\mathrm{NF}_{3}, p=0.075$ Torr, $P_{\mathrm{dlv}}=50 \mathrm{~W}$. 


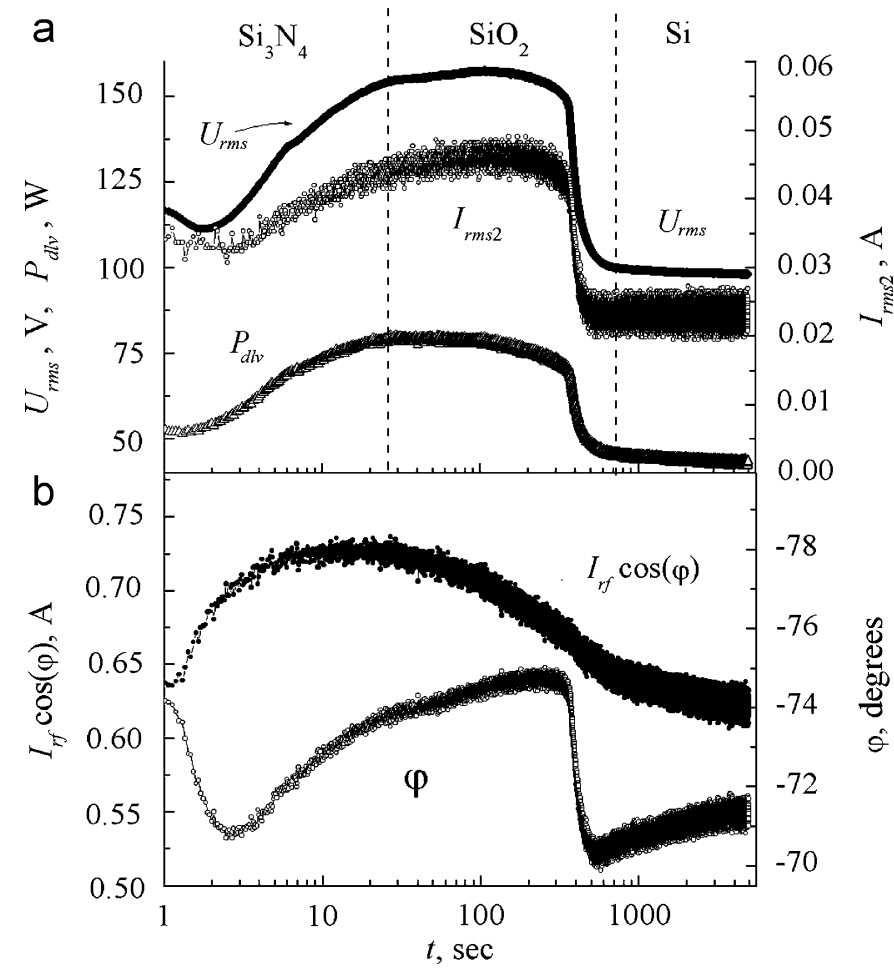

Fig. 5. Time dependence of the RF voltage $U_{\text {rms }}$, delivered power $P_{\mathrm{dlv}}$ and magnitude of the second harmonic of the discharge current $I_{\mathrm{rms} 2}(\mathrm{a})$, phase shift angle $\varphi$ and active RF current $I_{\mathrm{RF}} \cos (\varphi)$ (b) during etching of a $\mathrm{Si}_{3} \mathrm{~N}_{4} / \mathrm{SiO}_{2} / \mathrm{Si}$ substrate in $\mathrm{NF}_{3}, p=0.375$ Torr, $P_{\mathrm{dlv}}=50 \mathrm{~W}$.

The magnitude of the second harmonic of the discharge current $I_{\text {rms2 }}$ turned up to be very sensitive to the processes in the discharge. During $\mathrm{SiO}_{2}$ etching a small fluctuation of RF voltage occurred (from 159 to $162 \mathrm{~V}$, by $1.9 \%$ ), and the magnitude of the second harmonic of the current increased by $10.9 \%$. When the etching of the $\mathrm{SiO}_{2}$ layer came to an end, the RF voltage and phase shift angle increased and the discharge current decreased. While the RF voltage increased by 1.4 times, the magnitude of the second harmonic of the current decreased almost three times.

Fig. 5 shows the results obtained during etching of $\mathrm{Si}_{3} \mathrm{~N}_{4} / \mathrm{SiO}_{2} / \mathrm{Si}$ plates at the $\mathrm{NF}_{3}$ pressure of 0.375 Torr. The transition from the $\mathrm{Si}_{3} \mathrm{~N}_{4}$ layer to $\mathrm{SiO}_{2}$ was clearly marked by the variations of all characteristics except the phase shift angle, whereas the transition from the $\mathrm{SiO}_{2}$ layer to the silicon wafer was well distinguishable from the behaviour of all electrical characteristics except the active RF current. But at low pressure $(<0.1$ Torr $)$ the RF voltage and phase shift angle did not exhibit any variation, though the completion of the $\mathrm{SiO}_{2}$ layer etching was clearly marked by abrupt changes of all recorded electrical characteristics.

\section{Conclusion}

It may be concluded that monitoring the etching of multi-layered materials should preferably be done by following several discharge parameters, rather than only one, for instance the RF voltage alone. Under some etching conditions (variations of gas pressure, initial delivered power consumed by the discharge) some parameters may be insensitive to the etching completion of one layer and the etching beginning of another one. Under all the conditions investigated in this study, the magnitude of the current second harmonic $I_{\mathrm{rms} 2}$ turned out to be the most reliable parameter to monitor in order to register all transitions from one layer to another during the process of multi-layered materials etching (as well as to register the end-point of plasma cleaning). Other recorded parameters showed no sensitivity to layer-layer transitions under some conditions; therefore it is desirable to employ several parameters for more reliable end-point detection. The most effective methods are electrical, namely measuring the effective RF voltage $U_{\text {rms }}$, RF current (amplitude $I_{\text {rms }}$ and active $I_{\mathrm{RF}} \cos (\varphi)$ current), phase shift angle between current and voltage $\varphi$, and magnitude of the second harmonic of the discharge current $I_{\mathrm{rms} 2}$. These methods exhibit sensitive reactions to variations occurring in the discharge, e.g., the discharge moves from one place to another; and they more or less reliably register the end point of the etching or chamber cleaning process. Mass spectrometry to follow the intensity of the $\mathrm{SiF}_{3}^{+}$peak may also be successfully employed for monitoring etching and cleaning processes. With this method, the presence of a fused silica glass (or other silicon-containing material) may lead to an error in the measurement of the end point of chamber cleaning because the intensity of the $\mathrm{SiF}_{3}^{+}$peak starts to increase slowly again after the end of cleaning.

The processes of plasma cleaning a technological chamber covered with a silicon nitride $\left(\mathrm{Si}_{3} \mathrm{~N}_{4}\right)$ film, and of etching multi-layered $\mathrm{Si}_{3} \mathrm{~N}_{4} / \mathrm{SiO}_{2} / \mathrm{Si}$ and $\mathrm{SiO}_{2} / \mathrm{Si}$ materials in an RF capacitive discharge in $\mathrm{NF}_{3}$ were studied. Wafer etching and chamber cleaning were monitored with a quadruple mass spectrometer, and by registering the gas pressure, amplitude of the RF voltage, phase shift angle between current and voltage, active current, as well as the magnitude of the second harmonic of the RF current. A conclusion is drawn on the suitability of using the second harmonic of the RF current for end-point detection during etching of multi-layered materials and plasma cleaning of technological chambers. It is shown that cleaning a chamber with a complicated design or a non-uniform distribution of deposited film may be a two-stage process.

\section{Acknowledgement}

The authors express their gratitude to the UNAXIS France-Displays division, Palaiseau, France, for their financial support and for the equipment used in this study.

\section{References}

[1] Moreau WM. Semiconductor lithography. Principles, practices, and materials. New York, London: Plenum Press; 1988.

[2] Winters HF, Coburn JW. Surf Sci Rep 1992;65:161. 
[3] Aydil ES. Plasma etching, in encyclopedia of applied physics, vol. 14. VCH Publishers; 1996. p. 171.

[4] Shul RJ, Pearton SJ, editors. Handbook of advanced plasma processing techniques. Berlin: Springer; 2000.

[5] Govier RP, McCracken GM. J Vac Sci Technol 1970;7:552.

[6] Jones AW, Jones E, Williams EM. Vacuum 1973;23:227.

[7] Calder RS. Vacuum 1974;24:437.

[8] Dylla HF, Cohen SA, Rossnagel SM, McCracken GM, Staib Ph. J Vac Sci Technol 1980;17:286.

[9] Stori H. Vacuum 1983;33:171.

[10] Brooks NH, Petersen P, DIII-D Group. J Nucl Mater 1987; 145-147:770.

[11] Dylla HF. J Vac Sci Technol A 1988;6:1276.

[12] O'Kane DF, Mittal KL. J Vac Sci Technol 1974;11:567.

[13] Coburn JW. IEEE Trans Plasma Sci 1991;19:1048.

[14] Korzec D, Rapp J, Theirich D, Engemann J. J Vac Sci Technol A 1994;12:369.

[15] Kaufmann H. Surf Coat Technol 1995;74-75:23.

[16] Grun R. Surf Coat Technol 1995;74-75:598.

[17] Garke B, Edelmann C, Ehrt M. Vacuum 1996;47:383.

[18] Kersten H, Steffen H, Behnke JF. Surf Coat Technol 1996;86-87:762.

[19] Raoux S, Tanaka T, Bhan M, Ponnekanti H, Seamons M, Deacon T, et al. J Vac Sci Technol B 1999;17:477.

[20] Sobolewski MA, Steffens KL. J Vac Sci Technol A 1999;17:3281.

[21] Kastenmeier BEE, Oehrlein GS, Langan JG, Entley WR. J Vac Sci Technol A 2000;18:2102.

[22] Ullal SJ, Singh H, Daugherty J, Vahedi V, Aydil ES. J Vac Sci Technol A 2002;20:1195.

[23] Mezerette D, Belmonte Th, Hugon R, Henrion G, Czerwiec Th, Michel H. Surf Coat Technol 2003;169-170:181.

[24] Law VJ, Tait D. Vacuum 1998;49:273.

[25] Veprek S, Eckmann C, Elmer JT. Plasma Chem Plasma Process 1988;8:445.

[26] Field D, Hydes AJ, Klemperer DF. Vacuum 1984;34:347.

[27] Degenkolb E, Park KO, Shorter JB, Tabasky M. J Electrochem Soc 1985;132:2027.

[28] Allen RL, Moore R, Whelan M. J Vac Sci Technol B 1996;14:498.

[29] Yue HH, Qin SJ, Wiseman J, Toprac A. J Vac Sci Technol A 2001;19:66.

[30] Gillis HP, Gignac WJ. J Vac Sci Technol A 1986;4:696.
[31] Roland JP, Marcoux PJ, Ray GW, Rankin GH. J Vac Sci Technol A 1985;3:631.

[32] Thomas DJ, Southworth P, Flowers MC, Greef R. J Vac Sci Technol B 1990;8:1044.

[33] Cunge G, Chabert P, Booth J-P. Plasma Sources Sci Technol 1997;6:349.

[34] Booth J-P. Plasma Sources Sci Technol 1999;8:249.

[35] Cunge G, Chabert P, Booth J-P. J Appl Phys 2001;89:7750.

[36] Fendel P, Francis A, Czarnetzki U. Plasma Sources Sci Technol 2005; $14: 1$.

[37] Bulcourt N, Booth J-P, Hudson EA, Luque J, Mok DKW, Lee EP, et al. J Chem Phys 2004;120:9499.

[38] Nishizawa J, Hatasaka N. Thin Solid Films 1982;92:189.

[39] Wormhoudt J. J Vac Sci Technol A 1990;8:1722.

[40] Haverlag M, Stoffels WW, Stoffels E, Kroesen GMW, de Hoog FJ. J Vac Sci Technol A 1996;14:384.

[41] Raby BA. J Vac Sci Technol 1978;15:205.

[42] Coburn JW, Kay E. IBM J Res Develop 1979;23:33.

[43] Mutsukura N, Turban G. Vacuum 1989;39:579.

[44] Occhiello E, Garbassi F, Coburn JW. J Phys D 1989;22:983.

[45] Ukai K, Hanazawa K. J Vac Sci Technol 1979;16:385.

[46] Hitchman ML, Eichenberger V. J Vac Sci Technol 1980;17: 1378.

[47] Kawamoto Y, Hashimoto N. In: Proceedings of the 25th annual meeting of Applied Physics Society of Japan, Tokyo, Japan; 1978. p. 246.

[48] Nishizawa J, Hayasaka N. Thin Solid Films 1982;92:189.

[49] Bizyukov AA, Sereda ND, Farenic VI, Yunakov NN. Poverkhnost. Fizika, Khimiya, Mekhanika 1984;9:127 [in Russian].

[50] Koh ATC, Thornhill NF, Law VJ. Electron Lett 1999;35: 1383.

[51] Law VJ, Kenyon AJ, Thornhill NF, Srigengan V, Batty I. Vacuum 2000;57:351.

[52] Law VJ, Kenyon AJ, Thornhill NF, Seeds AJ, Batty I. J Phys D 2001;34:2726.

[53] Pagliarani A, Kenyon A, Thornhill N, Sirisena E, Lee K, Law V. Bull Am Phys Soc 2004;49:16.

[54] Franklin R, Braithwaite N. Bull Am Phys Soc 2004;49:28.

[55] Langan J, Maroulis P, Ridgeway R. Solid State Technol 1996;39:115. 